\title{
Integrating Unmanned Aerial Systems Into the Crop Production System Through On-Farm Research
}

\author{
Kevin A. Adkins ${ }^{1}$, Christen C. Bailey ${ }^{1} \&$ Aspen E. Taylor ${ }^{1}$ \\ ${ }^{1}$ College of Aviation, Embry-Riddle Aeronautical University, Daytona Beach, FL, USA \\ Correspondence: Kevin A. Adkins, College of Aviation, Embry-Riddle Aeronautical University, Daytona Beach, \\ FL, 32114, USA. E-mail: kevin.adkins@erau.edu
}

Received: April 4, 2018

Accepted: May 3, 2018 Online Published: June 15, 2018

doi:10.5539/jas.v10n7p10

URL: https://doi.org/10.5539/jas.v10n7p10

\begin{abstract}
Precision agriculture strives to manage variations in the field in order to increase yield while adapting input factors to preserve resources and decrease production costs. Unmanned aerial systems (UAS) are advancing precision agriculture by allowing for nondestructive and convenient, as well as cost and time efficient mapping of spatial variation in fields with higher spatial resolution than previous methods. However, while there is much anticipation regarding the potential role for UAS in precision agriculture, their role still requires additional application-based testing. The objective of this work was to explore how growers best integrate the UAS product into their farm workflow. Two on-farm investigations were undertaken with vegetable growers for the duration of a growing season. Combinations of two unique unmanned aircraft (UA) platforms fitted with two different multispectral sensors were used to gather spectral reflectance data. The investigations found that the UAS product enabled the growers to optimize their field management practices, while overcoming a labor shortage, and create a more sustainable operation.
\end{abstract}

Keywords: precision agriculture, unmanned aerial systems, unmanned aircraft, UAV, remote sensing, vegetation index, NDVI

\section{Introduction}

Growers are increasingly being tasked with producing more food with fewer resources while reducing their impact on the environment. The goal of meeting society's food needs without compromising the ability of future generations to meet their own is the aim of sustainable agriculture (Feenstra et al., 2018). In order to meet this goal, in conjunction with continuous population growth, innovation in agriculture must continue.

Sustainable agriculture is multifaceted and includes consideration of economic benefit, social consciousness, and environmental stewardship (Feenstra et al., 2018). In an industry that is experiencing continuous margin compression, knowing exactly when, where and what input factors to apply, and which not to, dictates profitability. Sustainable farming practices are also increasingly being demanded by consumers and communities. Environmentally responsible agriculture practices contribute to sustainability by minimizing air and water pollution, encouraging biodiversity, and managing water as a limited resource, while building and maintaining healthy soil (Feenstra et al., 2018). Precision farming champions the goals of sustainable agriculture by making more efficient use of input factors and thus decreasing the ecological footprint of a farm, while also saving the grower money and labor costs. The ready availability of quantifiable, high resolution, spatially explicit data is a key enabler of precision farming.

Precision agriculture strives to manage variations in the field in order to increase yield while adapting input factors to preserve resources and decrease production costs. Unmanned aerial systems (UAS), colloquially referred to as drones, are advancing precision agriculture by allowing for nondestructive, cost and time efficient, on demand, and convenient mapping of spatial variation in fields with higher spatial resolution than previous methods. This quantifiable data allows for field management practices to be optimized by meeting actual crop needs and thus minimizing the use of water, pesticides, herbicides and fertilizers by enabling variable rate application. Variable rate application helps to realize both economic and environmental benefits. Additionally, these benefits also translate to less reliance on human labor, thus improving productivity while further lowering production costs. 
While the use of remote sensing platforms, such as inhabited aircraft and satellites, have been used in precision agriculture for some time, the implementation of UAS into precision agriculture holds unique promise. Unmanned aircraft (UA) enable aerial imagery with greater resolution, a higher temporal frequency, and reduced costs. The ability of a UAS to obtain a spatial resolution on the order of centimeters and fly daily is in stark contrast to low resolution satellite imagery and manned aircraft overflights a few times a growing season. The availability of this nascent high spatial and temporal resolution data empowers the grower to more proactively manage crop health.

UA were first used in agriculture as far back as 1990 for the spraying of rice paddies (Sato, 2003). However, subsequent access to high quality global positioning system (GPS) signals and cost effective GPS receivers, advancements in integrated circuits and battery technology, and the miniaturization of aircraft systems has now led to the proliferation of small and affordable UAS for agriculture. UA, equipped with a wide variety of sensors, have more recently been shown to be effective in agriculture to manage irrigation (Gonzalez-Dugo, Goldhamer, Zarco-Tejada, \& Fereres, 2015), ascertain soil moisture (Hassan-Esfahani, Torres-Rua, Jensen, \& Mckee, 2017) discriminate plowing techniques (Tripicchio, Satler, Dabisias, Ruffaldi, \& Avizzano, 2015), investigate the microclimate over crops (Adkins \& Sescu, 2017), estimate yield (Geipel, Link, \& Claupein, 2014), and monitor crop stress (Stanton et al., 2017), amongst other uses.

While there is much anticipation regarding the potential role for UAS in precision agriculture, their use still requires additional investigation into how they can be most effectively implemented by commercial growers, as much of the research to date has taken place on research farms (Thomasson \& Valasek, 2016), (Elston, 2016), (Komp, 2018), (Bendig, Yu, \& Aasen, 2015), (Nebiker, Lack, Abächerli, \& Läderach, 2016). Consideration needs to be given as to how a grower best implements the technology into their farm and crop management workflow. The employment of new technology by a farmer in the absence of thorough on-farm evaluation, or knowledge of how best to integrate the technology into the farm workflow, presents a high risk. The main goal of this work was to investigate, in conjunction with the grower, how to best integrate UA-based multispectral imagery into crop management decisions. This investigation took place on two farms. Each grew an assortment of vegetables that included mustard greens, cabbage (white, Shanghai (bok choy), and wawa), and Chinese white radishes.

\section{Method}

Farmers today have many crop management tools and on-farm research can assist farmers in evolving their management strategies and decisions. This on-farm research utilized various state-of-the-art, commercial off-the-shelf (COTS) UA, sensors, and post-processing software. COTS hardware and software were chosen in order to make the operation viable to a representative farmer. Per the growers' feedback and acceptance, the acquisition, processing, analysis, and application of the data was continually adapted based on lessons learned. This evolution moved operations toward a pragmatic and relevant best practice. The overall generic UAS workflow consisted of flight planning, flight and the capturing of imagery, same day local processing of the data, and the creation of vegetation index maps. The sharing, analysis and ensuing discussion of the results informed the required actions on the part of the grower and established the timeframe for the next flight. All flight operations were conducted under 14 CFR Part 107 of the Federal Aviation Regulations (FAR). Furthermore, all crew members were certificated by the Unmanned Safety Institute (USI) in small UAS safety.

\subsection{System Description}

Commonly referred to as a drone, a UAS is a system comprised of a number of sub-systems to include the air vehicle (often called an unmanned aircraft (UA) or unmanned aerial vehicle (UAV)), the payload (sensors), a control station (CS) (most often a ground control station (GCS)), aircrew, data link, launch and recovery equipment, maintenance and support equipment, and an operational space consisting of rules and regulations (Austin, 2010). To make the operation and results applicable to the typical grower, two different, but widely available, fixed-wing UA were utilized. The majority of the flights were undertaken with the senseFly eBee, Figure 1a, with a few select flights completed with the Parrot Disco-Pro Ag, Figure 1b. Whenever the Disco Pro-Ag was deployed, the flight was immediately followed-up with the eBee platform for consistency. Flight planning for the eBee was accomplished using the accompanying eMotion software on a laptop, which also served as the GCS; planning for the Disco-Pro Ag flights was achieved with the Pix4Dcapture app on a mobile tablet. All data processing was completed using Pix4Dmapper Pro Ag. 

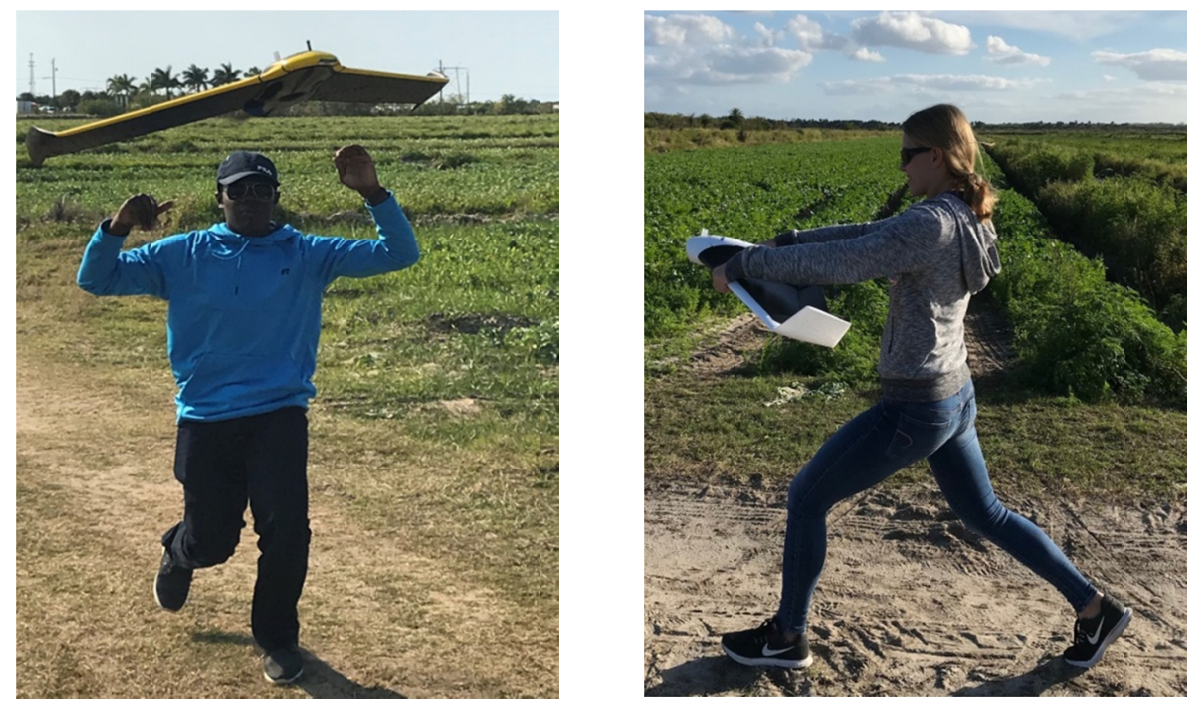

Figure 1. Launching of the unmanned aircraft: a) senseFly eBee; b) Parrot Disco-Pro Ag

\subsection{Data Acquisition}

The on-farm research was conducted on two expansive vegetable farms, totaling just over 81 hectares, in Florida (Figure 2). All flights took place with high sun angles between 1200 and 1500 local time and on cloud free days. Flights were conducted, at a minimum, on a weekly basis and more frequently when deemed necessary, or when monitoring the response of an applied field practice.

While often in a research setting and frequently by non-UA platforms, remote sensing, including the use of multispectral sensors (Nebiker, Annen, Scherrer, \& Oesch, 2008), has long been used to ascertain the health of crops (Bendig, Yu, \& Aasen, 2015), (Zecha, Link, \& Claupein, 2013), (Salamí, Barrado, \& Pastor, 2014), (Hatfield, Gitelson, Schepers, \& Walthall, 2008). The majority of the remote sensing for this investigation took place over cabbage and radish crops. While limited attention has been given to the remote sensing of cabbage in the literature, the use of reflectance spectra has been shown to be effective for the evaluation of cabbage growth and yield variations (Yang, Liu, \& Everitt, 2008). Additionally, it was observed that the reflectance of a healthy cabbage plant agrees with the reflectance behavior of normal plants.
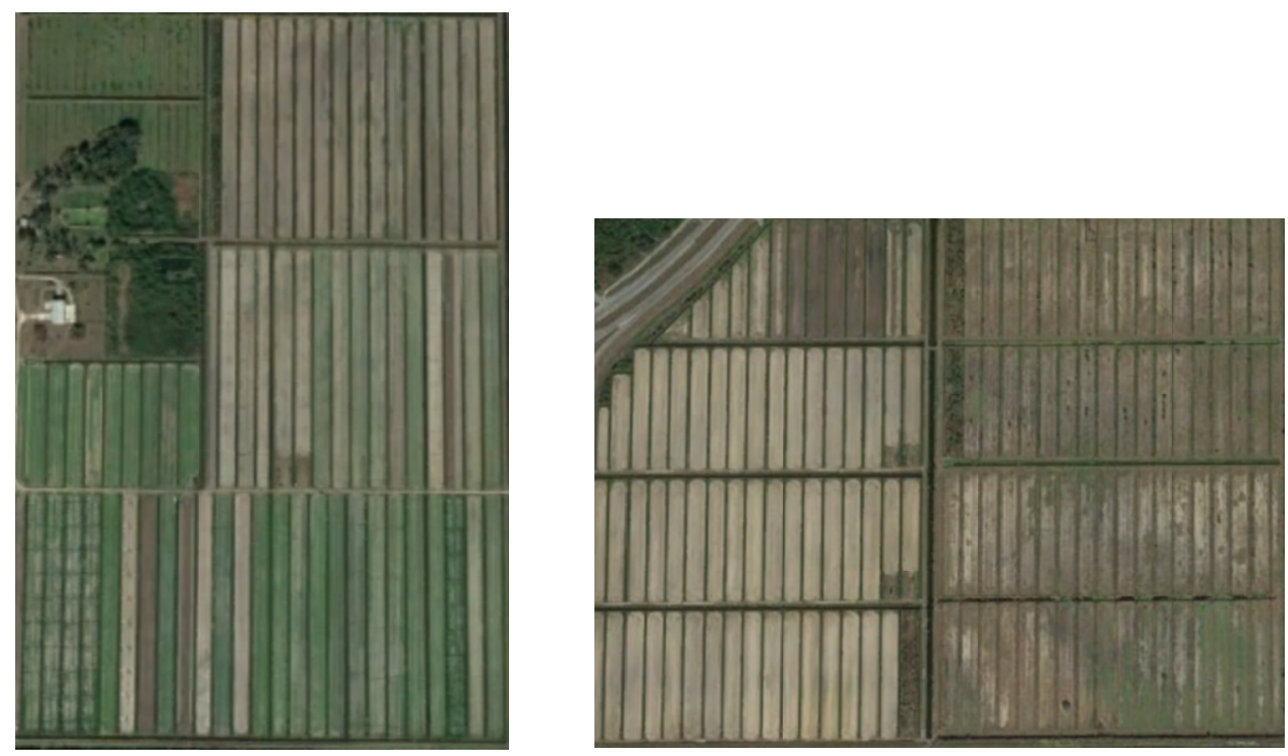

Images courtesy of Google Earth Pro.

Figure 2. Layout of two vegetable farms used for on-farm research 
Both the Airinov multiSPEC 4C and Parrot Sequoia multispectral sensors were employed during the field campaigns. Since only the multiSPEC $4 \mathrm{C}$ was available throughout the duration of the season, it was flown during every deployment for consistency. The in-flight performance of the multiSPEC $4 \mathrm{C}$ has been shown to compare very well with terrestrial reference data (Nebiker, Lack, Abächerli, \& Läderach, 2016). If a second flight was undertaken on the same day, the Sequoia sensor was then utilized. Each sensor and flight plan was configured to give a ground sampling distance (GSD) of $4.95 \mathrm{~cm}$ per pixel.

Both the Sequoia and multiSPEC 4C cameras capture four discrete spectral bands: green $(550 \mathrm{~nm})$, red $(660 \mathrm{~nm})$, red-edge $(735 \mathrm{~nm})$, and near infrared $(790 \mathrm{~nm})$, (multiSPEC 4C camera user manual, 2018), (Getting started with MicaSense, 2018). The bandwidths associated with the green, red, red-edge, and near infrared peaks are $40 \mathrm{~nm}$, $40 \mathrm{~nm}, 10 \mathrm{~nm}$, and $40 \mathrm{~nm}$ respectively. Figure 3 illustrates the wavelength response for both the multiSPEC 4C and Sequoia cameras. The green spectral band reflects a great deal of energy and correlates with leaf chlorophyll content. Red wavelengths have low reflectance, due to strong absorption, that varies as a function of biomass, leaf area index (LAI), soil minerals, humidity, and plant stress. The narrow band associated with red-edge is very sensitive to plant stress and an increase in reflectance of this band is often the result of nutrient stress. The near infrared wavelengths have strong reflectance that vary with crop type and plant vigor, with a reduction being associated with plant stress. The Sequoia camera also captures three non-discrete spectral bands with a RGB imager but these images were not utilized for the investigation. An irradiance sensor mounted on top of each sensor, in conjunction with a radiometric calibration undertaken just prior to every flight, allowed absolute reflectance measurements to be obtained and compared across all flights.

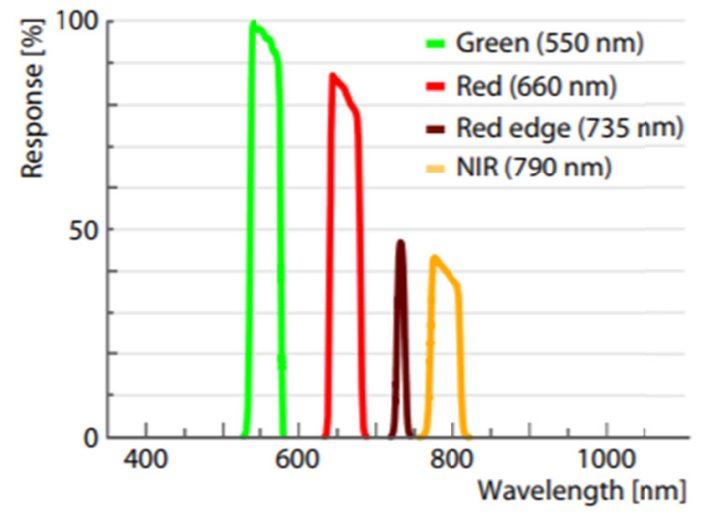

Image courtesy of senseFly.

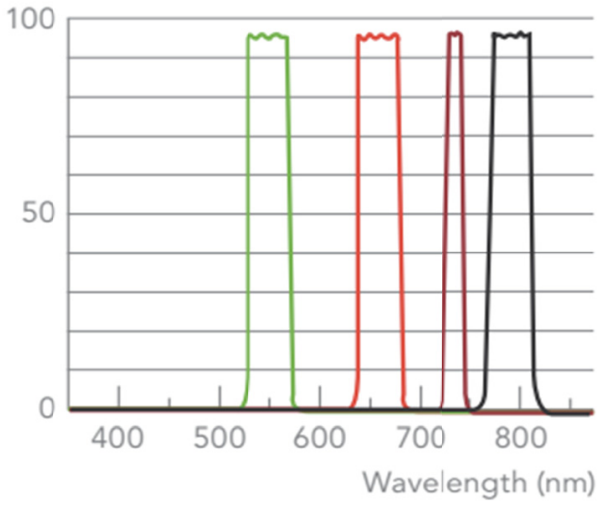

Image courtesy of MicaSense.

Figure 3. Wavelength response of 4 discrete spectral bands for: a) multiSPEC 4C; b) Sequoia

Vegetation indices (VIs) relate the reflectance from two or more spectral bands to various canopy characteristics such as health and density. First developed in the late 1960s (Gitelson, Kaufman, \& Merzlyak, 1969), many of the commonly used VIs are based on the bands used by the Landsat Earth-observing satellite program. The near infrared (NIR) band is incorporated into many of these VIs since it is not affected by pigments, such as chlorophyll. Consequently, the NIR band is frequently used to normalize the other chlorophyll-sensitive wavebands. VIs possess the ability to provide insight into the health of a plant that cannot necessarily be ascertained by the human eye.

Multiple VIs were calculated and resulting images analyzed early on in the on-farm research. Table 1 lists each of these VIs, along with the index's formula, that was preliminarily considered. The well-known, and often used, normalized difference vegetation index (NDVI), along with the green normalized difference vegetation index (GNDVI), were continually considered. Due to the success of Yang et al. (2008) with the red simple ratio (NR) and the green ratio vegetation index (GRVI) while working with cabbage, these VIs were also given consideration. Finally, with the goal of minimizing the soil background in order to enhance the vegetation signal, the soil adjusted vegetation index (SAVI) was also utilized when the crops were immature. Since the field was divided into subplots (see Figure 2) and planting and harvesting were staggered across these plots, the crop maturity varied within the field. Once all phases of crop maturity could be imaged in the field at least once, the original list of VIs was distilled down to three that all subsequent analysis took place with: NDVI, GNDVI, and SAVI. The SAVI includes an adjustment factor, $\mathrm{L}$, for soil reflectance. $\mathrm{L}$ ranges from 0 for very high vegetation 
cover, thus making it equivalent to the NDVI, to 1 in the absence of any green vegetation cover. The most commonly used value with the SAVI is 0.5 for intermediate vegetation cover. Following inspection of the fields, a ratio of 3:1 was assumed for bed row vegetation to tractor tire pathway soil (see Figure 4). Therefore, the SAVI was preliminarily considered with both the customary value of 0.5 and observed value of 0.25 . SAVI images with the observed value of 0.25 were found to be of greater benefit and this value was then carried through for all subsequent analysis.

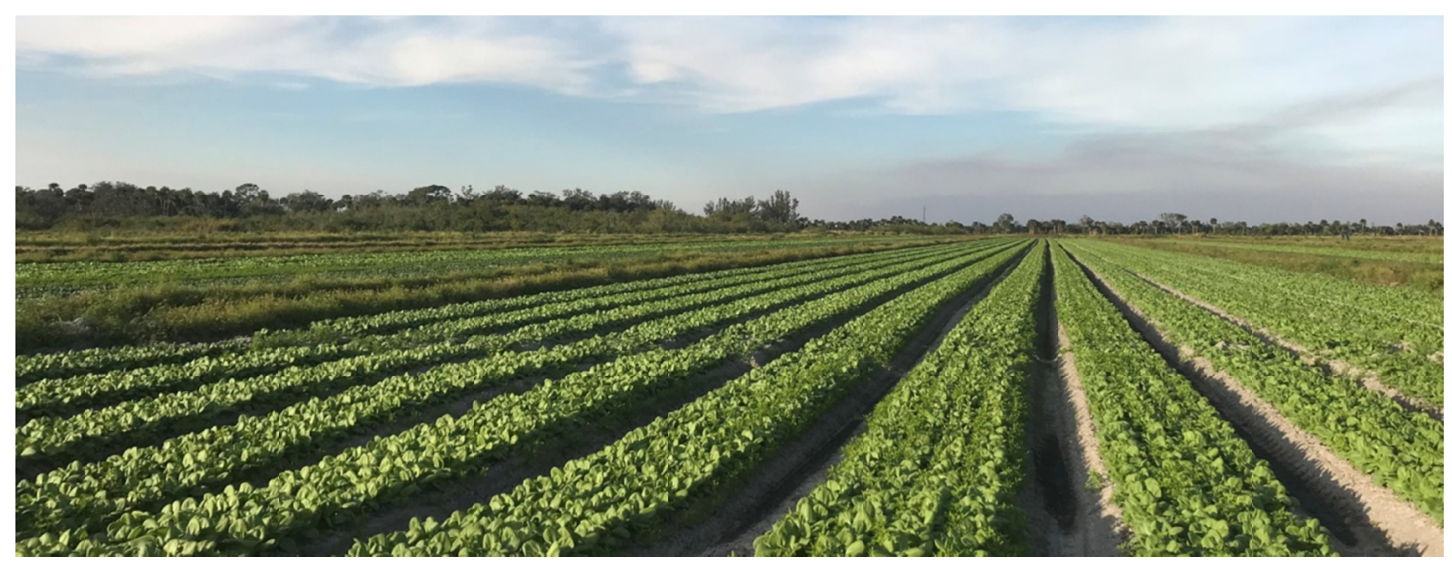

Figure 4. Layout of vegetable bed rows

Table 1. Summary of vegetation indices considered

\begin{tabular}{|c|c|c|c|}
\hline Index & Formula & Comments & Reference \\
\hline Normalized difference vegetation index (NDVI) & $\frac{N I R-\text { red }}{\text { NIR }+ \text { red }}$ & Measure of green vegetation & (Deering, 1978) \\
\hline $\begin{array}{l}\text { Green normalized difference vegetation } \\
\text { index (GNDVI) }\end{array}$ & $\frac{N I R-\text { green }}{N I R+\text { green }}$ & $\begin{array}{l}\text { Measures green versus } \\
\text { red spectrum in NDVI }\end{array}$ & $\begin{array}{l}\text { (Gitelson, Kaufman, } \\
\text { \& Merzlyak, 1996) }\end{array}$ \\
\hline Soil adjusted vegetation index (SAVI) & $\frac{(N I R-\text { red })(1+L)}{N I R+\text { red }+L}$ & $\begin{array}{l}\text { Accounts for soil background } \\
\text { in spectral reflectance }\end{array}$ & (Huete, 1988) \\
\hline Green chlorophyll index $\left(\mathrm{CI}_{\text {green }}\right)$ & $\left(\frac{N I R}{\text { green }}\right)-1$ & Assesses chlorophyll content & (Gitelson et al., 2003) \\
\hline Red-edge chlorophyll index ( $\left.\mathrm{CI}_{\text {red-edge }}\right)$ & $\left(\frac{N I R}{\text { red_edge }}\right)-1$ & Assesses chlorophyll content & (Gitelson et al., 2003) \\
\hline Red simple ratio (NR) & $\frac{N I R}{r e d}$ & Indicates amount of vegetation & (Jordan, 1969) \\
\hline Green ratio vegetation index (GRVI) & $\frac{\text { NIR }}{\text { green }}$ & Measure of green vegetation & $\begin{array}{l}\text { (Yang, Bradford, } \\
\& \text { Wiegand, 2001) }\end{array}$ \\
\hline
\end{tabular}

\section{Results and Discussion}

The remote sensing of the vegetable crops over the entirety of the growing season allowed for repeated measurements of the crops. Timely analysis of this data then allowed for the identification of spatial and temporal variations in the grower's fields. This information empowered the grower to make better informed crop management decisions and then, subsequently, monitor the efficacy of the specific action undertaken.

Early in the growing season, due to the relatively large soil background, SAVI maps were initially utilized to discriminate between crops and weeds and allowed for the monitoring of weed pressure. The identification of an area experiencing a high degree of weed pressure subsequently directed more efficient field walking. Observation of the area of concern then confirmed the plant species and weed density. These observations, coupled with an UAS-derived holistic coverage assessment, then informed the eradication strategy. Continued assessment of spatial and temporal changes in the field allowed for treatment effectiveness to be gauged. In previous seasons, an assessment of weed pressure within the field was achieved through human scouting. However, the labor intensive nature of this strategy necessitated sacrificing large spatial coverage for thorough 
inspection. The trade-off between extensive spatial coverage and exhaustive inspection was made especially acute during the associated growing season by the farm labor shortages experienced as the result of the simultaneous conversation in the United States regarding immigration and deportation policy. One of the earliest recognized benefits, by the grower, of the UAS was the comprehensive scouting it enabled in the midst of the labor shortage. The UAS thus enabled comprehensive, high resolution scouting that accounted for the irregular distribution of weeds. Further, analysis of SAVI and NDVI images during this stage of the season alerted the grower to planting and germination issues within the field.

The growing season in Florida largely coincides with the region's dry season and the period of time during which the investigation took place was abnormally dry with an absence of any precipitation in the fields for 3 months. In order to avoid excessive soil salinity realized from long-term subsurface irrigation (water table control), an irrigation gun was utilized during critical periods of crop development, and to activate fertilizer following its application. As crops matured, and crop canopy density increased, NDVI-derived maps were more singularly utilized to reveal heterogeneity within the fields. Areas identified as being stressed were specifically targeted for inspection. With the unusually dry growing season, the stress often identified was water stress. The high resolution NDVI map was then subsequently used to guide irrigation. This strategy minimized water usage and decreased the labor effort associated with the irrigation gun.

The ability to monitor temporal variation within the field through regular overflights allowed for the continued observation of plant growth and examination of crop health. In addition to red based NDVI, green based GNDVI images were created and shared with the grower for this purpose. These images helped inform the need for chemical treatment, the required rate of treatment, and allowed for the monitoring of the efficacy of the treatment. While the images readily identified areas needing attention, one benefit unanticipated by the growers was their ability to see the effectiveness of the treatment, specifically following fertilization, prior to being able to visually perceive it in the field through plant color. Figure 5 shows similarly scaled NDVI images taken of two adjacent subplots. The left-hand side of the field contained radish and the right-hand side contained cabbage. From left to right, the images in the figure show an image just prior to fertilization (left image), five days after fertilization (center image), and thirteen days following fertilization (right image). Each field was fertilized on the same day, with the fertilizer activated at the same time by irrigation. No further action was taken on either of the fields during the following two weeks and a uniform visual improvement in plant color was not observed until two weeks elapsed. However, the NDVI images clearly show an improvement in crop health prior to this point in time. The radish field, on the left-hand side, exhibits a swifter improvement than the cabbage field, on the right. The grower attributed this difference to the increased nutrient uptake associated with the increased surface area of this root vegetable. 

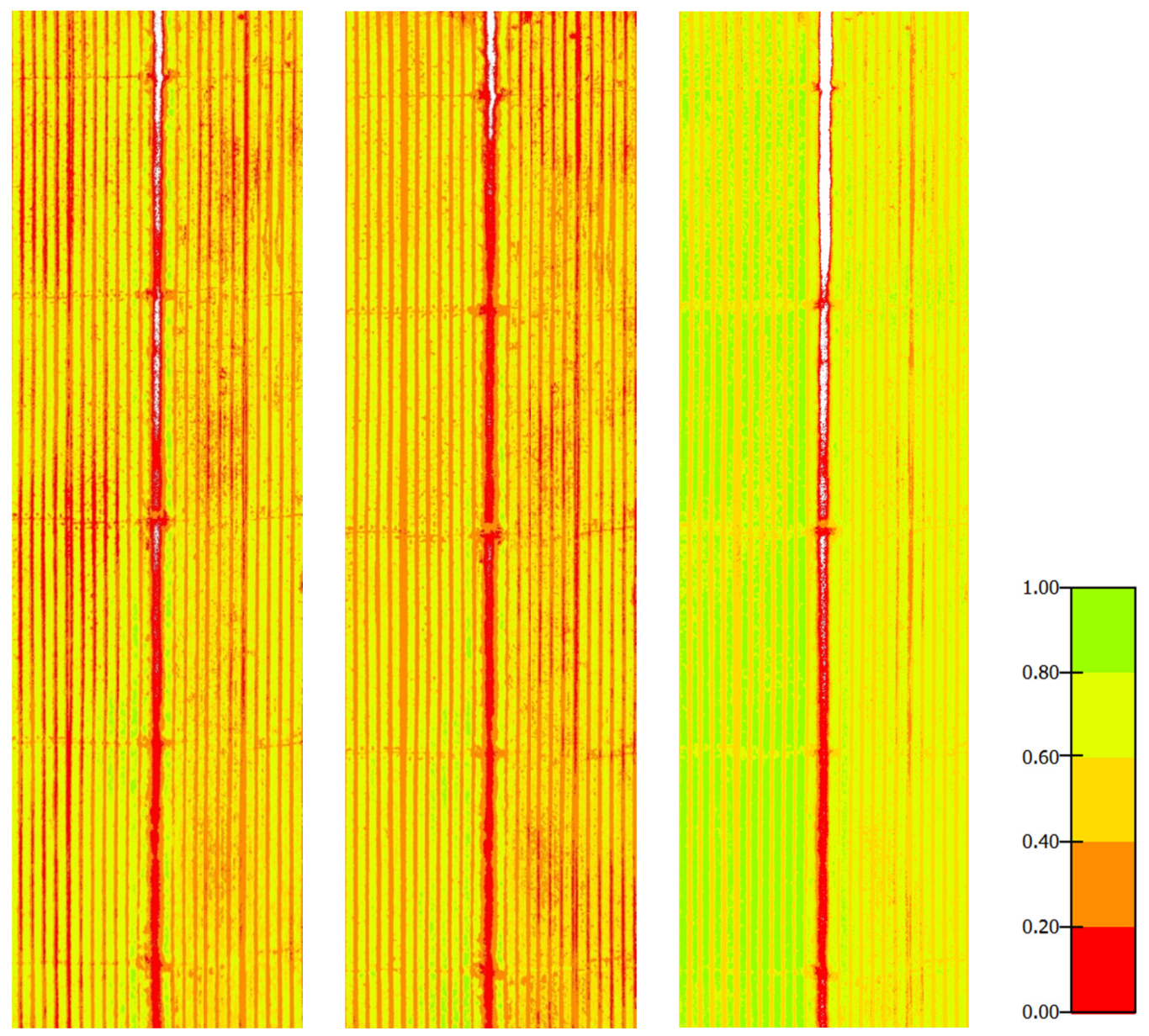

Figure 5. Similarly scaled NDVI images of 2 adjacent subplots with radish planted on the left and cabbage on the right: a) left image taken at time of fertilizer application; b) center image taken 5 days following fertilization; c) right image taken 13 days post fertilization

\section{Conclusion}

This investigation sought to better understand how to effectively integrate UAS technology into the farm workflow and use it for agronomic decision making beyond the structured setting of a research farm. Consequently, the work was undertaken as on-farm research, in conjunction with the grower, on two vegetable farms. A variety of vegetation indices that incorporated spectral reflectance in both the green and red ranges were analyzed in order to accommodate the entire range of chlorophyll variation. The resulting timely, convenient, and cost-effective high resolution imagery allowed for both the identification of in-field spatial variability, and the ability to compare these images over the entirety of the growing season. This insight enabled the tracking of crop growth and health that empowered the grower to more efficiently and effectively implement and monitor his crop management strategy, even in the midst of acute labor challenges. Thus, the implementation of an UAS into the farm workflow allowed the growers to optimize their field management practices and create a more sustainable operation.

\section{References}

Adkins, K. A., \& Sescu, A. (2017). Observations of Relative Humidity in the Near-wake of a Wind Turbine using an Instrumented Unmanned Aerial System. International Journal of Green Energy, 14(10), 845-860. https://doi.org/10.1080/15435075.2017.1334661

Austin, R. (2010). Unmanned Aircraft Systems: UAVs Design, Development and Deployment. Reston, VA: AIAA \& Wiley. https://doi.org/10.1002/9780470664797 
Bendig, J., Yu, K., \& Aasen, H. (2015). Combining UAV-based Plant Height from Crop Surface Models, Visible, and Near Infrared Vegetation Indices for Biomass Monitoring in Barley. International Journal of Applied Earth Observation and Geoinformation, 39, 79-87. https://doi.org/10.1016/j.jag.2015.02.012

Deering, D. W. (1978). Rangeland Reflectance Characteristics Measured by Aircraft and Spacecraft Sensors. ProQuest Dissertations Publishing.

Elston, J. (2016). Why Unmanned Aircraft for Agriculture? Engineering \& Technology for a Sustainable World, 23(4), 22.

Feenstra, G., Ingels, C., Campbell, D., Chaney, D., George, M., \& Bradford, E. (2018). What is Sustainable Agriculture? Retrieved March 18, 2018, from http://asi.ucdavis.edu/programs/sarep/about/what-is-sustain able-agriculture

Geipel, J., Link, J., \& Claupein, W. (2014). Combined Spectral and Spatial Modeling of Corn Yield based on Aerial Images and Crop Surface Models Acquired with an Unmanned Aircraft System. Remote Sensing, 6(11), 10335-10355. https://doi.org/10.3390/rs61110335

Getting Started with MicaSense. (2018). Retrieved March 22, 2018, from https://support.micasense.com/hc/ en-us/articles/217112037-What-spectral-bands-does-the-Sequoia-camera-capture

Gitelson, A. A., Kaufman, Y. J., \& Merzlyak, M. N. (1996). Use of a Green Channel in Remote Sensing of Global Vegetation from EOS-MODIS. Remote Sens. Environ., 58(3), 289-298. https://doi.org/10.1016/ S0034-4257(96)00072-7

Gitelson, A. A., Viña, A., Arkebauer, T. J., Rundquist, D. C., Keydan, G., \& Leavitt, B. (2003). Remote Estimation of Leaf Area Index and Green Leaf Biomass in Maize Canopies. Geophys. Res. Lett., 30(5), 335-343. https://doi.org/0.1029/2002GL016450

Gonzalez-Dugo, V., Goldhamer, D., Zarco-Tejada, P. J., \& Fereres, E. (2015). Improving the Precision of Irrigation in a Pistachio Farm using an Unmanned Airborne Thermal System. Irrig. Sci., 33(1), 43-52. https://doi.org/10.1007/s00271-014-0447-z

Hassan-Esfahani, L., Torres-Rua, A., Jensen, A., \& Mckee, M. (2017). Spatial Root Zone Soil Water Content Estimation in Agricultural Lands using Bayesian-Based Artificial Neural Networks and High-resolution Visual, NIR, and Thermal Imagery. Irrigation and Drainage, 66(2), 273-288. https://doi.org/10.1002/ ird.2098

Hatfield, J. L., Gitelson, A. A., Schepers, J. S., \& Walthall, C. L. (2008). Application of Spectral Remote Sensing for Agronomic Decisions. Agron. J., 100(Suppl. 3), 117. https://doi.org/10.2134/agronj2006.0370c

Huete, A. R. (1988). A Soil-adjusted Vegetation Index (SAVI). Remote Sensing of Environment, 25(3), $295-309$. https://doi.org/10.1016/0034-4257(88)90106-X

Jordan, C. F. (1969). Derivation of Leaf-area Index from Quality of Light on the Forest Floor. Ecology, 50(4), 663-666. https://doi.org/10.2307/1936256

Komp, M. (2018). Drones on the Farm. Retrieved March 20, 2018, from https://www.noble.org/news/ publications/legacy/2017/fall/drones-on-the-farm

multiSPEC 4C Camera User Manual. (2018). Retrieved April 4, 2018, from http://95.110.228.56/ documentUAV/camera\%20manual/[ENG]_2014_user_manual_multiSPEC_4C.pdf

Nebiker, S., Annen, A., Scherrer, M., \& Oesch, D. (2008). A Light-weight Multispectral Sensor for Micro UAV: Opportunities for Very High Resolution Airborne Remote Sensing. International Archives of the Photogrammetry, Remote Sensing and Spatial Information Sciences (pp. 1193-1200).

Nebiker, S., Lack, N., Abächerli, M., \& Läderach, S. (2016). Light-weight Multispectral UAV Sensors and their Capabilities for Predicting Grain Yield and Detecting Plant Diseases. International Archives of the Photogrammetry, Remote Sensing and Spatial Information Sciences (XLI-B1, pp. 963-970). https://doi.org/ 10.5194/isprsarchives-XLI-B1-963-2016

Salamí, E., Barrado, C., \& Pastor, E. (2014). UAV Flight Experiments Applied to the Remote Sensing of Vegetated Areas. Remote Sensing, 6(11). https://doi.org/10.3390/rs61111051

Sato, A. (2003). The RMAX Helicopter UAV. Defense Technical Information Center. Retrieved from http://www.dtic.mil/docs/citations/ADA427393 
Stanton, C., Starek, M. J., Elliott, N., Brewer, M., Maeda, M. M., \& Chu, T. (2017). Unmanned Aircraft System-derived Crop Height and Normalized Difference Vegetation Index Metrics for Sorghum Yield and Aphid Stress Assessment. Journal of Applied Remote Sensing, 11(2), https://doi.org/10.1117/1.JRS. 11.026035

Thomasson, J. A., \& Valasek, J. (2016). Small UAS in Agricultural Remote-sensing Research at Texas A\&M. Resource: Engineering \& Technology for a Sustainable World, 16(4), 19.

Tripicchio, P., Satler, M., Dabisias, G., Ruffaldi, E., \& Avizzano, C. A. (2015). Towards Smart Farming and Sustainable Agriculture with Drones (pp. 140-143). 2015 International Conference on Intelligent Environments (IE). https://doi.org/10.1109/IE.2015.29

Yang, C., Bradford, J. M., \& Wiegand, C. L. (2001). Airborne Multispectral Imagery for Mapping Variable Growing Conditions and Yields of Cotton, Grain Sorghum, and Corn. Trans ASAE, 44(6), https://doi.org/ $10.13031 / 2013.6997$

Yang, C., Liu, T., \& Everitt, J. H. (2008). Estimating Cabbage Physical Parameters using Remote Sensing Technology. Crop Protection, 27(1), 25-35. https://doi.org/10.1016/j.cropro.2007.04.015

Zecha, C. W., Link, J., \& Claupein, W. (2013). Mobile Sensor Platforms: Categorization and Research Applications in Precision Farming. Journal of Sensors and Sensor Systems, 2(1), 51-72. https://doi.org/ $10.5194 /$ jsss-2-51-2013

\section{Copyrights}

Copyright for this article is retained by the author(s), with first publication rights granted to the journal.

This is an open-access article distributed under the terms and conditions of the Creative Commons Attribution license (http://creativecommons.org/licenses/by/4.0/). 